\title{
PRIMARY CREEP IN NICKEL-BASE SUPERALLOYS
}

\author{
Dilip M. Shah, S. Vega, S. Woodard, Alan D. Cetel \\ Pratt \& Whitney; 400 Main Street; East Hartford, CT, 06457, USA
}

Keywords: primary creep, crystal orientation, shape change, ellipticity

\begin{abstract}
The nature of primary creep and intermediate temperature creep behavior of nickel base superalloys is reexamined. An extensive analysis of creep data for several $2^{\text {nd }}, 3^{\text {rd }}$, and later generation single crystal alloys, with nominal $<100>$ orientation is presented. It is shown that even though primary creep appears to vary in a complex manner with orientation, heat treatment and alloy chemistry, considerable clarity in data analysis can be gained if the associated variation in non-uniform deformation is taken into account. The non-uniform deformation may be quantified by measuring the ratio of major to minor diameters, or ellipticity, of the cylindrical specimens after test. Analysis shows that the logarithm of rupture life linearly decreases and final elongation linearly increases with ellipticity. It is theorized that while the association of high creep elongation with high ellipticity is a natural consequence of the conservation of volume, the decline in rupture life with increasing ellipticity is probably a result of progressively higher average true stress, under a constant load creep test condition. It is further shown that while the nonuniform deformation is a strong function of orientation, the maximum degree of ellipticity attained may be structure sensitive and may vary with alloy chemistry, heat treatment, stress and temperature.
\end{abstract}

\section{Introduction}

The origin of extensive primary creep in cast nickel-base superalloys, in the intermediate temperature range, has been a subject of many investigations over nearly the last 37 years. Unfortunately each investigation had a narrow focus and was limited to either a single alloy, often with no variation in heat treatment, or with limited number of tests and few variations in crystal orientation. The academic nature of many of such studies may be a direct consequence of a lack of engineering interest in the intermediate temperature creep behavior. This has been the case, in spite of the observations of unusually high primary creep strains and non-uniform deformation of single crystal specimens. However, with increasing demand for temperature capability, performance and durability, coupled with increasing component complexity, this aspect can no longer be treated as an object of mere academic curiosity. For the purpose of this paper we are specifically limiting our discussion to creep behavior between $700^{\circ}-850^{\circ} \mathrm{C}\left(1300-1600^{\circ} \mathrm{F}\right)$, at stresses in excess of $551 \mathrm{MPa}(80$ ksi).

In the earliest work on single crystal superalloys by Kear and Piearcey (1967)[1], it was observed that high primary creep occurred at intermediate temperatures $\left(760^{\circ} \mathrm{C}\right)$ only, and the orientation dependence of primary creep suggested that it was associated with single-slip deformation. Based on further analysis, Paslay et al., (1970)[2], asserted that the primary creep rate for a variety of orientations can be best represented by emphasizing the $\{111\}<112>$ slip systems in preference to $\{111\}<110>$ slip. Leverant and Duhl (1971)[3], however, showed that high primary creep also occurred in coarse grained, and directionally solidified columnar-grain materials. They also observed that while primary creep strain decreases with reduced stress, the time to complete primary creep increases with decreasing stress. Additionally, they also observed that primary creep strain is suppressed by the introduction of a fine-scale substructure upon shock loading. Following this early work, Lin Dongliang et al. (1984)[4] more systematically explored the nature of primary creep in columnar grain materials.

More than a decade later, Caron et al. (1988)[5] showed that the primary creep behavior was even more complex than envisioned. Their study of three major orientations demonstrated that both incubation period and primary creep are a function of orientation and $\gamma^{\prime}$ precipitate size. Recently Kakehi (2000)[6] has corroborated these findings and has shown that primary creep is affected by cooling rates, which influence the fine precipitate structure. Primary creep was also observed to be a function of major (Shah and Cetel, 1996)[7] and minor (Shah and Duhl, 1988)[8], alloying additions to single crystal superalloys. However, based on extensive analysis of $<100>$ oriented single crystal superalloy CMSX-3, Pollock and Argon (1992)[9] concluded that primary creep following the initial incubation period was a result of initial thermal misfit stresses developed between the $\gamma$ and $\gamma^{\prime}$ phases, and that it was unrelated to any work-hardening or recovery processes. In contrast, Miura et al. (1991)[10] argue that in single phase $\gamma^{\prime}-\mathrm{Ni}_{3}(\mathrm{Al}, \mathrm{X})$, the initial sigmoidal behavior is a reflection of the yield point behavior observed under constant tensile strain rate testing. Again in contrast to Pollock and Argon (1992)[9], and in agreement with Kear and Piearcey (1967)[1], Zhu et al. (1998)[11, 12], studying $\mathrm{Ni}_{3}(\mathrm{Al}, \mathrm{Ta})$ in various orientations concluded octahedral slip to be responsible for primary creep, while cube-cross slip contributed to secondary creep. Further Zhu et al., (1998)[11, 12], conclude that blocking of the edge dislocations by forest dislocations cause their climb and termination of primary creep. Added to this debate in recent years, is finally some attempt to correlate the non-uniform deformation with crystal orientation and active slip systems [13, 14].

This paper is an attempt to bring some engineering discipline to these diverse studies based on analysis of some well-documented existing data for nominally $<100>$ oriented columnar grain and single crystal alloys. It is concluded that while the intermediate temperature primary creep behavior is perhaps the most structure and orientation sensitive aspect of mechanical behavior of superalloy single crystals, the often observed non-uniform deformation in itself is a major source of variation. It has not been recognized that variation can be an artifact of non-uniform deformation leading to a significant rise in true stress during a constant load creep test. Taking these factors in to account, a new 
methodology to normalize the data is proposed and its empirical and theoretical validity is demonstrated.

\section{Experimental Procedure}

This work is primarily directed at analyzing creep data for columnar grain and single crystal alloys generated between $700^{\circ}$ $850^{\circ} \mathrm{C}\left(1300-1600^{\circ} \mathrm{F}\right)$. The creep test results reported here were not carried out in any systematic manner with the objective of analyzing primary creep, but were retroactively retrieved because of our renewed interest in primary creep. All data are based on testing of nominally $56 \mathrm{~mm}$ (2.23") long threaded cylindrical specimens with a $19 \mathrm{~mm} \times 3.2 \mathrm{~mm}$ dia. $(0.75$ " x 0.125 " dia.) cylindrical gauge section. Records confirm that all specimens were creep tested using constant load machines and standard ASTM practice was followed.

Reexamination of the available specimens indicated that in many cases the deformation had occurred non-uniformly, and the cross section of the gauge area of the failed specimens was visibly elliptical. In all available specimens where the test was carried out to rupture, the final major $\left(\mathbf{d}_{\text {fmax }}\right)$, and minor $\left(\mathbf{d}_{\text {fmin }}\right)$ diameters of the specimens were measured. A typical example of a metallographic cross section of an elliptical gauge area is shown in Figure 1, which shows the minor axis to be parallel to $\langle 110>$ direction. As discussed later this cannot be construed to imply that slip exclusively occurs with $<110>$ slip vector.

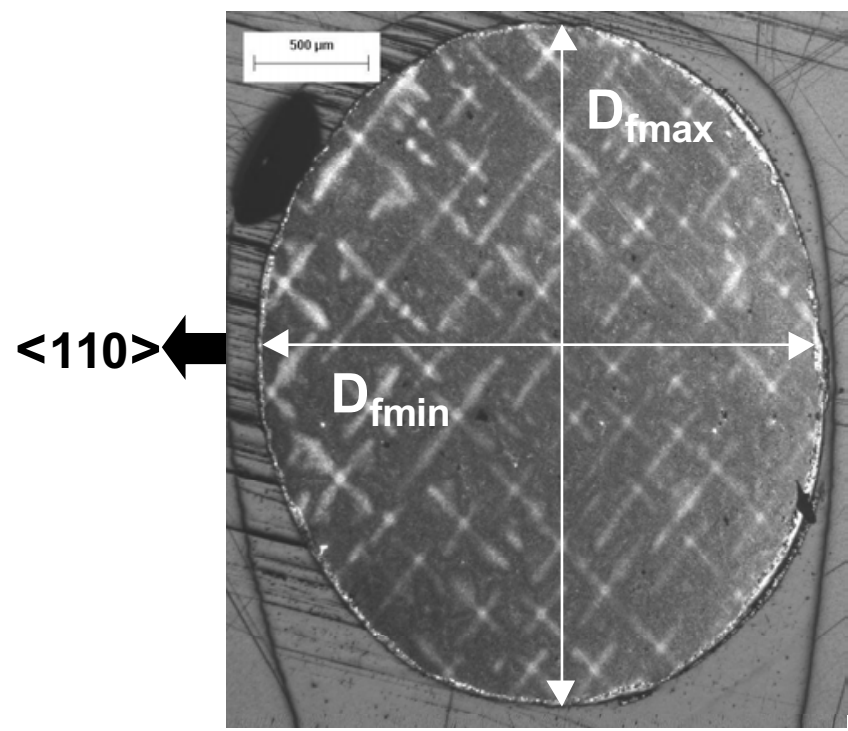

Figure 1. A typical metallographic cross section of a nonuniformly deformed creep specimen. The dendritic pattern indicates the minor axis to be parallel to the $<110>$ direction.

Whenever possible, the crystallographic orientation of the specimen axis was determined with X-ray Laue diffraction using the grip ends of specimens. In the absence of Laue data for an individual specimen, the orientation of the specimen axis was assumed to be the same as the average orientation of the original single crystal bar from which it was procured.
All specimens were machined from fully heat-treated material. The heat treat cycle typically consists of a solution heat treatment, a coating simulation cycle, and a final aging cycle at a lower temperature. Variation in heat treatments is noted wherever relevant throughout the paper, and for brevity the abbreviations used to label heat treatments are listed in Table I.

Table I. Abbreviation Used to Designate Heat Treatments

\begin{tabular}{|c|l|}
\hline Abbreviation & \multicolumn{1}{|c|}{ Heat Treatment } \\
\hline SHT & $\begin{array}{l}\text { Solution Heat Treatment: } 2400^{\circ} \mathrm{F} / 30 \mathrm{~min}, \\
\text { Fast Cool }\end{array}$ \\
\hline C & $\begin{array}{l}\text { Simulated Coating Cycle: } 1975^{\circ} \mathrm{F} / 4 \\
\text { hours, Fast Cool }\end{array}$ \\
\hline VHT & $\begin{array}{l}\text { Aging Treatment: Typically }>1600^{\circ} \mathrm{F} \text { for } \\
>10 \text { hours }\end{array}$ \\
\hline HT & Aging Treatment: $1600^{\circ} \mathrm{F} / 32$ hours \\
\hline HTS & Aging Treatment: $1600^{\circ} \mathrm{F} / 8$ hours \\
\hline HTL & Aging Treatment: $1600^{\circ} \mathrm{F} />100$ hours \\
\hline IT & Aging Treatment: $1500^{\circ} \mathrm{F} / 8$ hours \\
\hline LT & Aging Treatment: $1300^{\circ} \mathrm{F} / 24$ hours \\
\hline
\end{tabular}

Alloys for which creep data are presented in this paper include columnar grain (CG) PWA1422 (Mar-M200+Hf), PWA1480, PWA1484 and similar $2^{\text {nd }}$ generation single crystal alloys, and several $3^{\text {rd }}$ and $4^{\text {th }}$ generation single crystal alloys containing high levels of $\mathrm{Re}, \mathrm{Ru}$ and other refractory elements. Alloy compositions are not listed in this paper as that information is not particularly relevant to the principal theme of the paper.

\section{Results}

As presented in Figure 2, a cursory comparison of primary creep at $816^{\circ} \mathrm{C} / 621 \mathrm{MPa}\left(1500^{\circ} \mathrm{F} / 90 \mathrm{ksi}\right)$ of several nominally $<100>$ oriented columnar grain and single crystal alloys may suggest alloy composition to be a major influencing factor. While this is partially true, further investigation suggests that primary creep is also a strong function of either heat treatment or orientation, or both factors, for a given alloy.

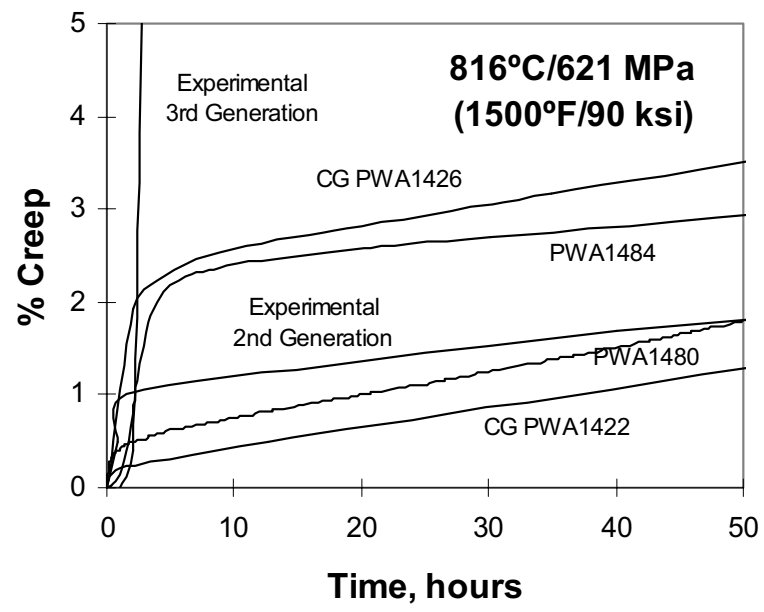

Figure 2. Primary creep in various, fully heat-treated, columnar grain and single crystal alloys. 
The effect of heat treatment on primary creep can be seen, both in the case of directionally solidified CG (columnar grain) PWA1422 and single crystal PWA1484, as shown in Figures 3(a) and (b), respectively. Abbreviated labels on each creep curves in the figure denote the heat treatment, as listed in Table I. While it may be assumed that no orientation consideration is necessary in the longitudinal direction for nominally $<100>$ textured columnar grain material, the situation is not as simple in the case of single crystal alloys. The primary creep behavior is known to be a function of crystal orientation and the anisotropic behavior can be a strong function of heat treatment.

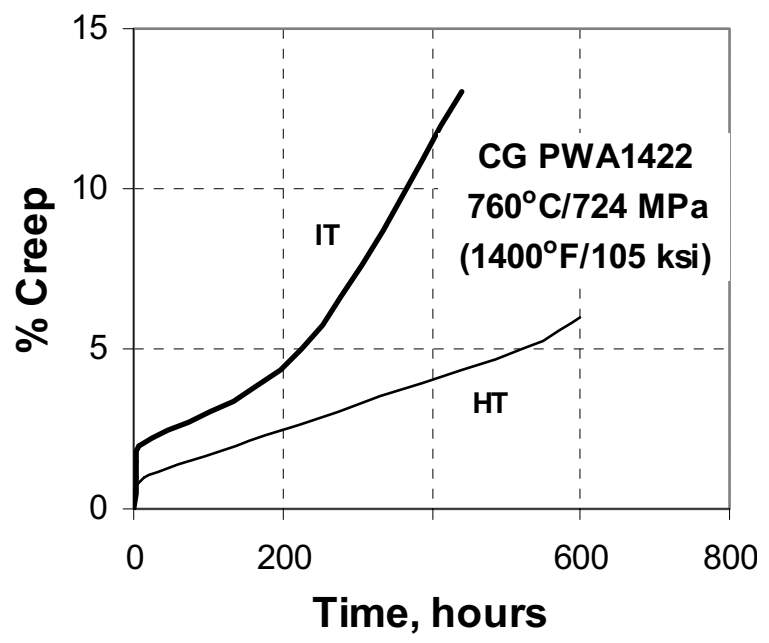

(a)

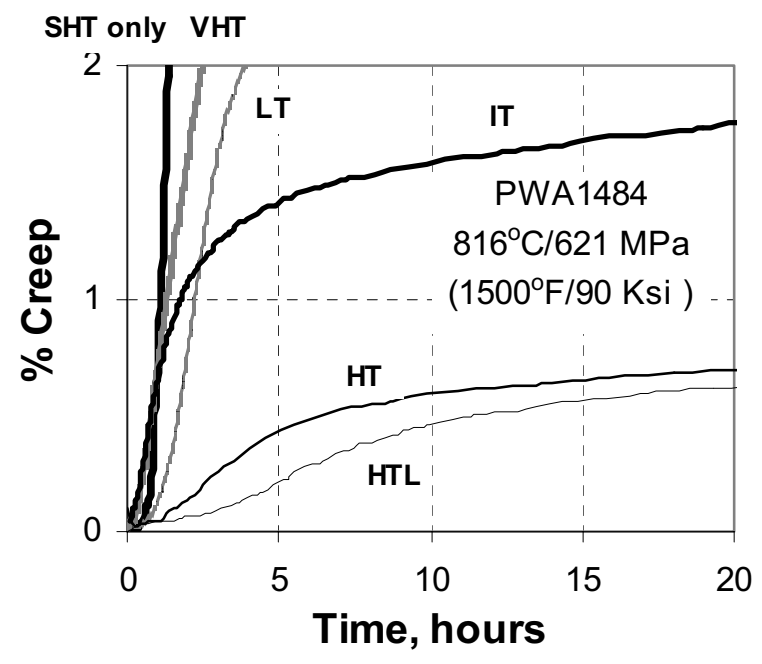

(b)

Figure 3. Effect of final heat treatments on primary creep of nominally $<100>$ oriented (a) CG (columnar grain) PWA 1422 and (b) single crystal PWA 1484. Labels denote heat treatments as listed in Table I.
As shown in Figure 4(a), while the primary creep at $816^{\circ} \mathrm{C} / 621 \mathrm{MPa}\left(1500^{\circ} \mathrm{F} / 90 \mathrm{ksi}\right)$ for PWA1484 is a strong function of orientation for one heat treatment, it is rather insensitive to orientation for the other. As depicted with reference to a standard orientation triangle in Figure 4(b), crystal orientations of the specimens in Figure 4(a) are well dispersed over the orientation space in the vicinity of $\langle 100\rangle$. Note that almost identically oriented specimens DL and DH show a huge variation in primary creep response resulting from different heat treatments. Since many of these tests were terminated earlier for other reasons, only partial data corresponding to these tests are listed in Table II.

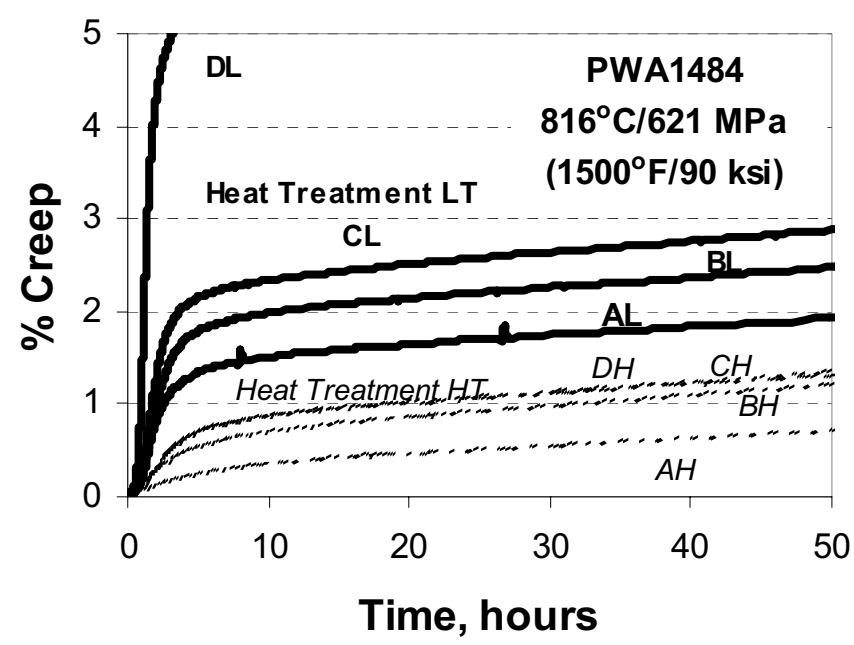

(a)

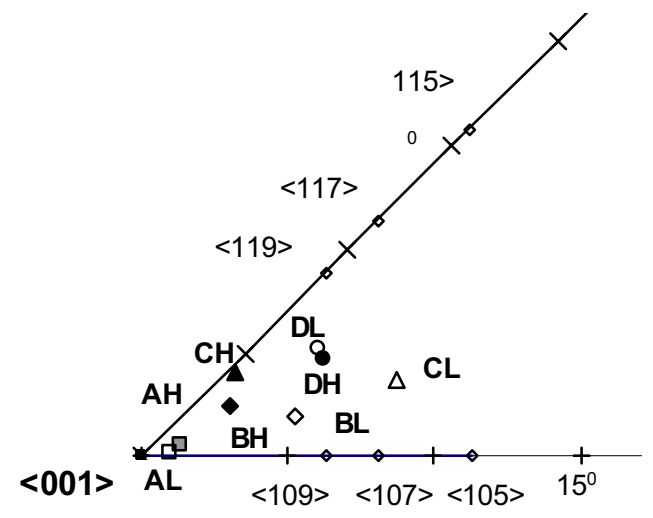

(b)

Figure 4. (a) Primary creep behavior of PWA 1484 at $816^{\circ} \mathrm{C} / 621 \mathrm{MPa}\left(1500^{\circ} \mathrm{F} / 90 \mathrm{ksi}\right)$ with two different heat treatments, each with four specimens of comparable axial orientations, and (b) the actual orientations of specimens as plotted on a section of the stereographic triangle near $\langle 100\rangle$. Labels correspond to specimen identification listed in Table II. 
Table II is critical to the presentation of results and for further discussion. Listed in the table are the specimen identification, heat treatment, orientation, creep test conditions and results, initial and final diameters, ellipticity of final gauge section, and calculated value of true stress at failure. The orientation is listed as Miller indices using two digits, such that $<001>$ is equivalent to $<00,00,99>$. In this notation a one digit difference between say $<08,09,99>$ and $<07,09,99>$ is approximately $0.58^{\circ}$, which is better than the precision of Laue analysis.

In sharp contrast to the interplay between heat treatments and orientations at $816^{\circ} \mathrm{C}\left(1500^{\circ} \mathrm{F}\right)$, shown in Figure 4, the behavior at a lower temperature and higher stress was shown to be a strong function of orientation, but not of heat treatment. Four groups of specimens with different heat treatments were creep tested at $732^{\circ} \mathrm{C} / 758 \mathrm{MPa}\left(1350^{\circ} \mathrm{F} / 110 \mathrm{ksi}\right)$. Surprisingly, even though three groups of specimens were machined from only two single crystal bars, characterized as being $4.8^{\circ}$ and $5.9^{\circ}$ off $\langle 100\rangle$, respectively, an eight-fold variation in ductility and rupture life was observed! Early portions of the creep curves are shown in Figure 5(a), and the axial orientation for each specimen is mapped out in the orientation triangle presented in Figure 5(b). The labels in the figure denote heat treatment and specimen number as per Tables I and II. Note that the extremes in the creep behavior are more or less a function of axial orientation of the specimens, and occur with any heat treatment. In general, orientations closer to the $<100>-<111>$ boundary display high primary creep, high ductility and low rupture life. Data corresponding to these tests are also listed in Table II.

Table II. Compilation of Intermediate Temperature Creep Data for PWA 1484 and Several Experimental Alloys

\begin{tabular}{|c|c|c|c|c|c|c|c|c|c|c|c|c|c|c|c|c|}
\hline Alloy & $\begin{array}{c}\text { Specimen } \\
\text { Number }\end{array}$ & \begin{tabular}{|c|} 
Heat \\
Treatment
\end{tabular} & $\begin{array}{c}\text { Deviation } \\
\alpha \text { from } \\
<100>\end{array}$ & Orientation & Temp. & \begin{tabular}{|c|} 
Initial \\
Stress \\
$\sigma_{0}$
\end{tabular} & $\begin{array}{c}\text { Time } \\
\text { to } \\
1 \%\end{array}$ & \begin{tabular}{|c|} 
Time \\
to \\
$2 \%$
\end{tabular} & $\begin{array}{c}\text { Rupture } \\
\text { Life }\end{array}$ & $\begin{array}{l}\text { Creep } \\
\text { Elong. }\end{array}$ & \begin{tabular}{|c|} 
Initial \\
Dia. \\
$\mathbf{d}_{0}$
\end{tabular} & $\begin{array}{l}\text { Final } \\
\text { Maj. } \\
\text { Dia. } \\
\mathbf{d}_{\text {fmax }}\end{array}$ & $\begin{array}{l}\text { Final } \\
\text { Min. } \\
\text { Dia. } \\
\mathbf{d}_{\text {fmin }} \\
\end{array}$ & $\begin{array}{c}\text { Diameter } \\
\text { Ratio } \\
\mathbf{d}_{\text {fmax }} / \mathbf{d}_{\text {fmin }}\end{array}$ & \begin{tabular}{|c|} 
Final \\
Stress \\
$\sigma_{\mathrm{f}}$
\end{tabular} & \begin{tabular}{|c|} 
Increase \\
in \\
Stress \\
$\% \Delta \sigma$ \\
$\%$
\end{tabular} \\
\hline & & & degrees & $<\mathrm{hh}, \mathrm{kk}, \mathrm{ll}>$ & ${ }^{\circ} \mathrm{C}$ & $\mathrm{MPa}$ & hrs & hrs & hrs & $\%$ & $\mathrm{~mm}$ & $\mathrm{~mm}$ & $\mathrm{~mm}$ & & $\mathrm{MPa}$ & $\%$ \\
\hline \multicolumn{17}{|c|}{ PWA1484 816 ${ }^{\circ} \mathrm{C} / 621 \mathrm{Mna}$ Creen Test Results } \\
\hline PWA1484 & $\mathrm{AH}$ & $\mathrm{S}+\mathrm{C}+\mathrm{IT}$ & 1.4 & $<02,10,99>$ & 815.6 & 620.6 & 83 & 184.7 & Discont. & & & & & & & \\
\hline PWA1484 & $\mathrm{BH}$ & $\mathrm{S}+\mathrm{C}+\mathrm{IT}$ & 3.3 & $<05,30,99>$ & 815.6 & 620.6 & 31.3 & 125.4 & Discont. & & & & & & & \\
\hline PWA1484 & $\mathrm{CH}$ & $\mathrm{S}+\mathrm{C}+\mathrm{IT}$ & 4.3 & $<06,50,99>$ & 815.6 & 620.6 & 20.5 & 115 & Discont. & & & & & & & \\
\hline PWA1484 & DH & $\mathrm{S}+\mathrm{C}+\mathrm{IT}$ & 7.1 & $<11,60,99>$ & 815.6 & 620.6 & 18.3 & 136 & Discont. & & & & & & & \\
\hline PWA1484 & $\mathrm{AL}$ & $\mathrm{S}+\mathrm{C}+\mathrm{LT}$ & 1.0 & $<02,00,99>$ & 815.6 & 620.6 & 2.5 & 59 & Discont. & & & & & & & \\
\hline PWA1484 & $\mathrm{BL}$ & $\mathrm{S}+\mathrm{C}+\mathrm{LT}$ & 4.8 & $<09,20,99>$ & 815.6 & 620.6 & 2.1 & 10.9 & Discont. & & & & & & & \\
\hline PWA1484 & $\mathrm{CL}$ & $\mathrm{S}+\mathrm{C}+\mathrm{LT}$ & 8.6 & $<15,05,99>$ & 815.6 & 620.6 & 1.7 & 3.7 & Discont. & & & & & & & \\
\hline PWA1484 & DL & $\mathrm{S}+\mathrm{C}+\mathrm{LT}$ & 7.1 & $<11,60,99>$ & 815.6 & 620.6 & 0.9 & 1.2 & Discont. & & & & & & & \\
\hline \multicolumn{17}{|c|}{ PWA1484 $732^{\circ} \mathrm{C} / 759 \mathrm{Mpa}$ Creep Test Results } \\
\hline PWA1484 & IT1 & $\mathrm{S}+\mathrm{C}+\mathrm{IT}$ & 4.2 & $<07,10,99>$ & 732.2 & 758.5 & 2.4 & 3.4 & 389 & 20.0 & 3.18 & 3.07 & 2.62 & 1.1748 & 950.9 & 25.4 \\
\hline PWA1484 & IT2 & $\mathrm{S}+\mathrm{C}+\mathrm{IT}$ & 6.6 & $<10,50,99>$ & 732.2 & 758.5 & 2.4 & 3.8 & 340 & 13.0 & 3.12 & 3.12 & 2.87 & 1.0885 & 821.5 & 8.3 \\
\hline PWA1484 & IT3 & $\mathrm{S}+\mathrm{C}+\mathrm{IT}$ & 6.5 & $<10,60,99>$ & 732.2 & 758.5 & 1.9 & 2.6 & 140 & 32.0 & 3.15 & 3.15 & 2.41 & 1.3053 & \begin{tabular}{|l|}
993.2 \\
\end{tabular} & 30.9 \\
\hline PWA1484 & HTS4 & $\mathrm{S}+\mathrm{C}+\mathrm{HTS}$ & 7.9 & $\mid<14,10,99>$ & \begin{tabular}{|l|}
732.2 \\
\end{tabular} & \begin{tabular}{ll|}
758.5 \\
\end{tabular} & 2.6 & 3.6 & 127 & 25.0 & 3.14 & 3.07 & 2.51 & 1.2222 & \begin{tabular}{|l|}
965.7 \\
\end{tabular} & 27.3 \\
\hline PWA1484 & HTS5 & $\mathrm{S}+\mathrm{C}+\mathrm{HTS}$ & 6.5 & $<11,40,99>$ & 732.2 & 758.5 & 2.9 & 3.9 & 141 & 28.0 & 3.14 & 3.12 & 2.44 & 1.2813 & \begin{tabular}{|l|}
984.4 \\
\end{tabular} & 29.8 \\
\hline PWA1484 & HTS6 & $\mathrm{S}+\mathrm{C}+\mathrm{HTS}$ & 4.7 & $<08,30,99>$ & \begin{tabular}{|l|}
732.2 \\
\end{tabular} & 758.5 & 3.4 & 6.1 & 332 & 8.0 & 3.13 & 3.07 & 3.05 & 1.0083 & \begin{tabular}{|l|}
795.4 \\
\end{tabular} & 4.9 \\
\hline PWA1484 & HTS7 & $\mathrm{S}+\mathrm{C}+\mathrm{HTS}$ & 6.8 & $<09,80,99>$ & \begin{tabular}{|l|}
732.2 \\
\end{tabular} & 758.5 & 2 & 2.6 & 46 & 37.0 & 3.21 & 3.12 & 2.24 & 1.3977 & 1119. & 47.6 \\
\hline PWA1484 & HTS8 & $\mathrm{S}+\mathrm{C}+\mathrm{HTS}$ & 7.9 & $<10,90,99>$ & \begin{tabular}{|l|}
732.2 \\
\end{tabular} & 758.5 & 2 & 2.6 & 68 & 38.0 & 3.19 & 3.12 & 2.26 & 1.3820 & 1091. & 43.9 \\
\hline PWA1484 & HTS9 & $\mathrm{S}+\mathrm{C}+\mathrm{HTS}$ & 5.6 & $<09,20,99>$ & \begin{tabular}{|l|}
732.2 \\
\end{tabular} & 758.5 & 2.7 & 4.2 & 356 & 15.0 & 3.15 & 3.10 & 2.90 & 1.0702 & \begin{tabular}{|l|}
837.2 \\
\end{tabular} & 10.4 \\
\hline PWA1484 & HTS10 & $\mathrm{S}+\mathrm{C}+\mathrm{HTS}$ & 6.5 & $<11,30,99>$ & \begin{tabular}{|l|}
732.2 \\
\end{tabular} & \begin{tabular}{|l|}
758.5 \\
\end{tabular} & 2.4 & 3.3 & 224 & 26.0 & 3.17 & 3.10 & 2.51 & 1.2323 & \begin{tabular}{|l|}
979.6 \\
\end{tabular} & 29.2 \\
\hline PWA1484 & HT11 & $\mathrm{S}+\mathrm{C}+\mathrm{HT}$ & 7.8 & $<11,80,99>$ & \begin{tabular}{|l|}
732.2 \\
\end{tabular} & 758.5 & 2.3 & 2.8 & 62 & 35.0 & 3.22 & 3.18 & 2.34 & 1.3587 & 1060. & 39.8 \\
\hline PWA1484 & HT12 & $\mathrm{S}+\mathrm{C}+\mathrm{HT}$ & 4.5 & $<08,00,99>$ & \begin{tabular}{|l|}
732.2 \\
\end{tabular} & \begin{tabular}{|l|}
758.5 \\
\end{tabular} & 3.4 & 4.5 & 402 & 28.0 & 3.24 & 3.10 & 2.59 & 1.1961 & \begin{tabular}{|l|}
990.8 \\
\end{tabular} & 30.6 \\
\hline PWA1484 & HT13 & $\mathrm{S}+\mathrm{C}+\mathrm{HT}$ & 4.2 & $<07,00,99>$ & \begin{tabular}{|l|}
732.2 \\
\end{tabular} & 758.5 & 3.1 & 4.3 & 265 & 13.0 & 3.25 & 3.15 & 3.00 & 1.0508 & 846.6 & 11.6 \\
\hline PWA1484 & LT14 & $\mathrm{S}+\mathrm{C}+\mathrm{LT}$ & 1.0 & $<02,00,99>$ & \begin{tabular}{|l|}
732.2 \\
\end{tabular} & 758.5 & 4.8 & 6.2 & \begin{tabular}{|l|} 
Discont. \\
\end{tabular} & & & & & & & \\
\hline PWA1484 & LT15 & $\mathrm{S}+\mathrm{C}+\mathrm{LT}$ & 7.1 & $<11,60,99>$ & 732.2 & 758.5 & 3.5 & 4.1 & \begin{tabular}{|l|} 
Discont. \\
\end{tabular} & & & & & & & \\
\hline \multicolumn{17}{|c|}{ Experimental Alloys $816^{\circ} \mathrm{C} / 621 \mathrm{Mpa}$ Creep Test Results } \\
\hline $\mathrm{X} 1$ & $\mathrm{X1a}$ & $\mathrm{S}+\mathrm{C}+\mathrm{HT} 2$ & 1.6 & $<02,20,99>$ & 815.6 & 620.6 & 308.4 & 381.2 & 504 & 9.1 & 3.18 & 3.13 & 3.09 & 1.0129 & 646.8 & 4.2 \\
\hline $\mathrm{X} 1$ & $\mathrm{X} 1 \mathrm{~b}$ & $\mathrm{~S}+\mathrm{C}+\mathrm{HT} 2$ & 5.6 & $<07,70,99>$ & 815.6 & 620.6 & 272.3 & 336.2 & 421 & 6.7 & 3.20 & 3.17 & 3.13 & 1.0128 & 640.6 & 3.2 \\
\hline $\mathrm{X} 2$ & $\mathrm{X} 2 \mathrm{a}$ & $\mathrm{S}+\mathrm{C}+\mathrm{HT} 2$ & & & 815.6 & 620.6 & 26.2 & 44.3 & 706 & 18.5 & 3.15 & 2.98 & 2.79 & 1.0681 & 740.4 & 19.3 \\
\hline $\mathrm{X} 2$ & $\mathrm{X} 2 \mathrm{~b}$ & $\mathrm{~S}+\mathrm{C}+\mathrm{HT} 2$ & & & 815.6 & 620.6 & 18.9 & 25.5 & 319 & 23.4 & 3.18 & 3.18 & 2.64 & 1.2045 & 745.1 & 20.1 \\
\hline $\mathrm{X} 2$ & $\mathrm{X} 2 \mathrm{c}$ & $\mathrm{S}+\mathrm{C}+\mathrm{HT} 2$ & & & \begin{tabular}{|l|}
815.6 \\
\end{tabular} & 620.6 & 16 & 19 & 75 & 34.7 & 3.15 & 3.21 & 2.49 & 1.2892 & 770.2 & 24.1 \\
\hline $\mathrm{X} 2$ & $\mathrm{X} 2 \mathrm{~d}$ & $\mathrm{~S}+\mathrm{C}+\mathrm{HT} 2$ & & & \begin{tabular}{|l|}
815.6 \\
\end{tabular} & 620.6 & 48.3 & 67.8 & 151 & 7.3 & 3.09 & 3.12 & 2.97 & 1.0513 & 636.6 & 2.6 \\
\hline $\mathrm{X} 3$ & $\mathrm{X} 3 \mathrm{a}$ & $\mathrm{S}+\mathrm{C}+\mathrm{HT} 2$ & & & \begin{tabular}{|l|}
815.6 \\
\end{tabular} & 620.6 & 15.2 & 18.8 & 353 & 23.4 & 3.18 & 3.17 & 2.72 & 1.1654 & 725.5 & 16.9 \\
\hline $\mathrm{X} 3$ & $\mathrm{X} 3 \mathrm{~b}$ & $\mathrm{~S}+\mathrm{C}+\mathrm{HT} 2$ & & & \begin{tabular}{|l|}
815.6 \\
\end{tabular} & 620.6 & 23.7 & 32.9 & 823 & 15.3 & 3.14 & 3.05 & 2.81 & 1.0854 & 712.5 & 14.8 \\
\hline $\mathrm{X} 3$ & $\mathrm{X} 3 \mathrm{c}$ & $\mathrm{S}+\mathrm{C}+\mathrm{HT} 2$ & & & 815.6 & 620.6 & 16.2 & 20 & 479 & 25.9 & 3.16 & 3.1 & 2.64 & 1.1742 & \begin{tabular}{|l|}
758.3 \\
\end{tabular} & 22.2 \\
\hline $\mathrm{X} 4$ & $\mathrm{X} 4 \mathrm{a}$ & $\mathrm{S}+\mathrm{C}+\mathrm{HT} 2$ & 2.0 & $<02,20,99>$ & \begin{tabular}{|l|}
815.6 \\
\end{tabular} & 620.6 & 48.1 & 90.8 & 1072 & 12.1 & 3.20 & 3.01 & 2.92 & 1.0308 & 722.0 & 16.4 \\
\hline $\mathrm{X} 4$ & $\mathrm{X} 4 \mathrm{~b}$ & $\mathrm{~S}+\mathrm{C}+\mathrm{HT} 2$ & 2.0 & $<02,20,99>$ & \begin{tabular}{|l|}
815.6 \\
\end{tabular} & 620.6 & 48.4 & \begin{tabular}{|l|}
84.8 \\
\end{tabular} & 968 & 12.7 & 3.18 & 3.05 & 2.86 & 1.0664 & \begin{tabular}{|l|}
717.1 \\
\end{tabular} & 15.6 \\
\hline $\mathrm{X} 5$ & $\mathrm{X} 5 \mathrm{a}$ & $\mathrm{S}+\mathrm{C}+\mathrm{HT} 2$ & 2.9 & $<05,20,99>$ & \begin{tabular}{|l|}
815.6 \\
\end{tabular} & 620.6 & 39.1 & 82 & 1029 & 19.5 & 3.18 & 2.99 & 2.87 & 1.0418 & 729.0 & 17.5 \\
\hline $\mathrm{X} 5$ & $\mathrm{X} 5 \mathrm{~b}$ & $\mathrm{~S}+\mathrm{C}+\mathrm{HT} 2$ & 3.7 & $<06,00,99>$ & \begin{tabular}{|l|}
815.6 \\
\end{tabular} & 620.6 & 20.7 & 26.4 & 433 & 28.8 & 3.18 & 3.1 & 2.47 & 1.2551 & \begin{tabular}{|l|}
818.3 \\
\end{tabular} & 31.9 \\
\hline $\mathrm{X} 6$ & X6a & $\mathrm{S}+\mathrm{C}+\mathrm{HT} 2$ & 2.0 & $<03,20,99>$ & 815.6 & 620.6 & 143.4 & 267.7 & 740 & 24.3 & 3.18 & 3.19 & 2.74 & 1.1642 & 719.1 & 15.9 \\
\hline $\mathrm{X} 6$ & X6b & $\mathrm{S}+\mathrm{C}+\mathrm{HT} 2$ & 3.9 & $<07,10,99>$ & 815.6 & 620.6 & 62.2 & 120.6 & 526 & 26.2 & 3.18 & 3.15 & 2.56 & 1.2305 & 778.2 & 25.4 \\
\hline
\end{tabular}




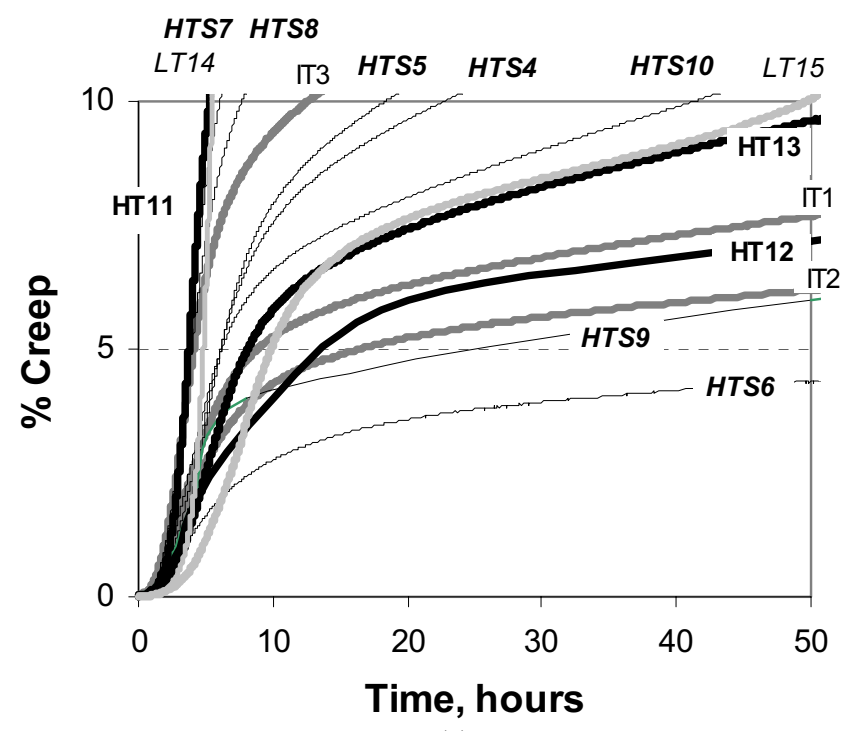

(a)

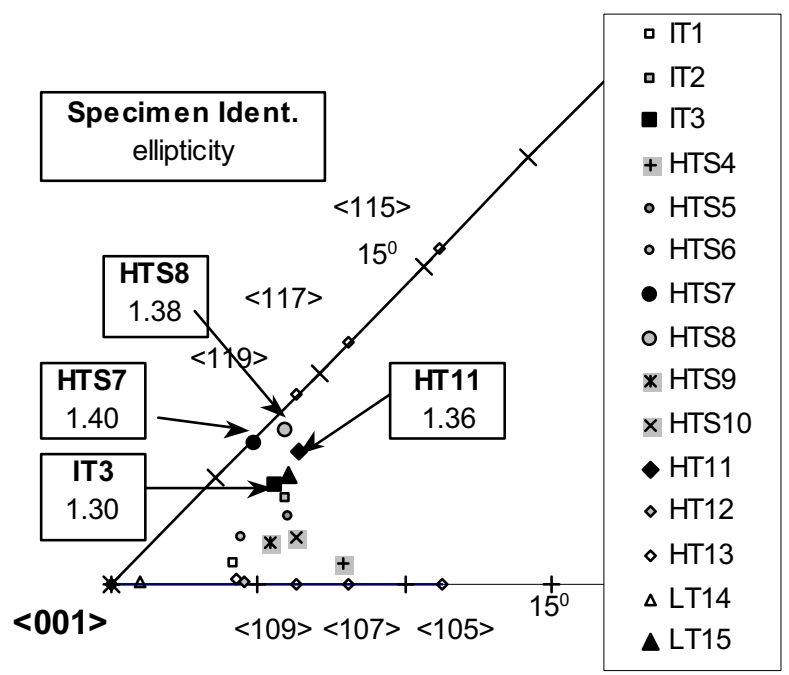

(b)

Figure 5. (a) Primary creep behavior of PWA 1484 at $732^{\circ} \mathrm{C} / 758 \mathrm{MPa}\left(1350^{\circ} \mathrm{F} / 110 \mathrm{ksi}\right)$ with four groups of specimens with comparable axial orientations, but with different heat treatments and (b) the actual orientations plotted on a section of the stereographic triangle near $\langle 100\rangle$. Labels denote the heat treatment and specimen number as listed in Tables I and II.

Additionally it was observed that specimens which manifested high ductility and low rupture life also deformed very nonuniformly. The initial round cross section of the specimen generally turned visibly elliptical as is shown in Figure 1. Note, it is very evident from the dendritic pattern in Figure 1, that thinning of the specimen occurs along a $<110>$ direction. In contrast, specimens showing low ductility, and long rupture life, deformed uniformly, preserving the round cross section.
Surprisingly, these observations aren't merely qualitative. As shown in Figures 6 (a) and (b), logarithm of rupture life and percent creep elongation, respectively, show a reasonable linear correlation with the final ellipticity $\left(\mathbf{d}_{\text {fmax }} / \mathbf{d}_{\text {fmin }}\right)$ of the specimen cross section, as measured by the ratio of maximum $\left(\mathbf{d}_{\text {fmax }}\right)$ to minimum $\left(\mathbf{d}_{\mathbf{f m i n}}\right)$ diameters. Note that equation of the best-fit line and the parameter $\mathrm{R}^{2}$ indicating its statistical significance are also quoted in the figures for further discussion. The simple correlation between ductility and the ellipticity of the specimens can be rationalized on the basis of preservation of volume, but the apparently simple semi-log correlation between the rupture life and the ellipticity defies a simple explanation. However, as discussed in detail later, this too can be simply rationalized on the basis that under a constant load creep test, the true stress at failure increases with increasing ellipticity.

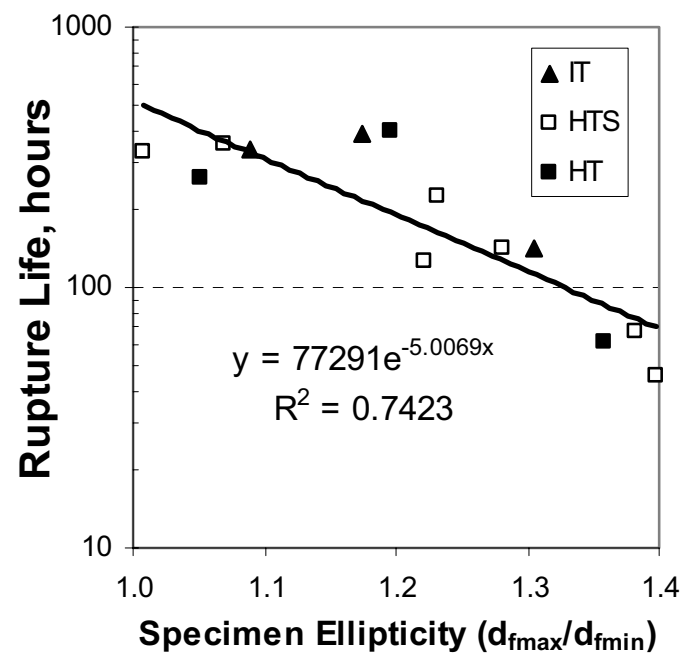

(a)

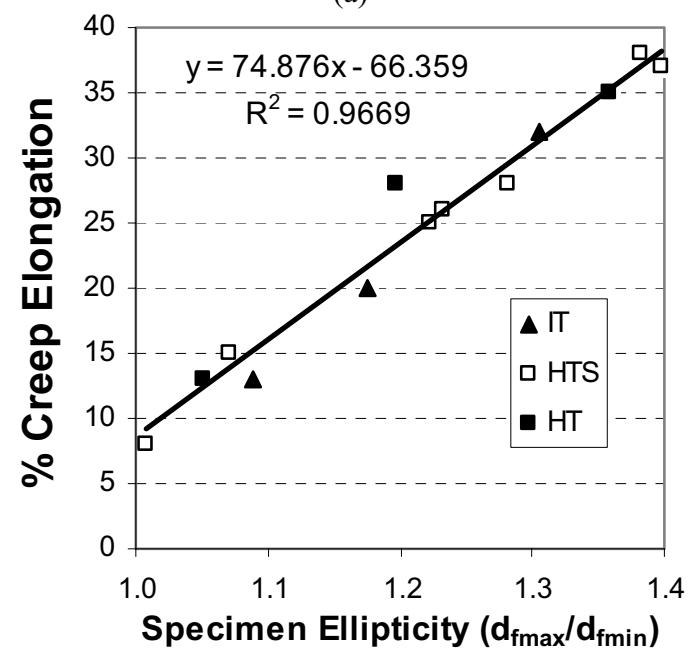

(b)

Figure $6.732^{\circ} \mathrm{C} / 758 \mathrm{MPa}\left(1350^{\circ} \mathrm{F} / 110 \mathrm{ksi}\right)$ (a) creep rupture life and (b) percent creep elongation versus specimen ellipticity of thirteen PWA 1484 single crystal specimens with three different heat treatments and varying specimen orientations as depicted in Figure $5(\mathrm{~b})$. Data points are segregated by heat treatments as listed in the legend using abbreviation defined in Table I. 
In order to test the universal validity of these observations, similar creep test data for several $4^{\text {th }}$ generation experimental alloys were collected as listed in Table II and subjected to the same analysis. Available orientation information is graphically presented in Figure 7 and individual data points are labeled with alloy designation, rupture life, percent elongation, and ellipticity. Similar to Figure 6, plots of rupture life and percent elongation versus ellipticity are presented in Figures 8(a) and (b), respectively. In Figure 8(a) individual best-fit lines are shown for each alloy, as rupture life is expected to vary with alloy composition. However, in Figure 8(b), no distinction between alloys is made, as correlation between percent elongation and ellipticity is expected to be purely a reflection of volume conservation.

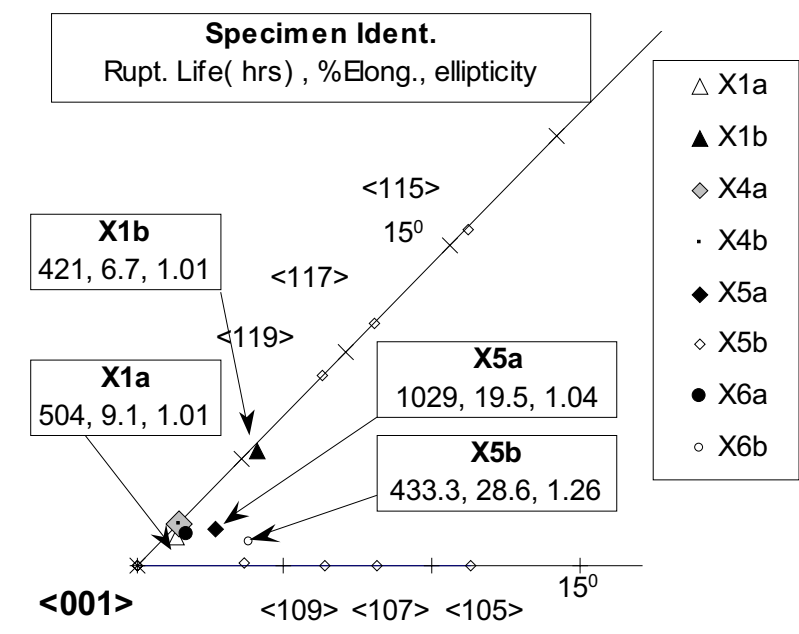

Figure 7. Rupture life of some $4^{\text {th }}$ generation experimental alloys at $816^{\circ} \mathrm{C} / 621 \mathrm{MPa}\left(1500^{\circ} \mathrm{F} / 90 \mathrm{ksi}\right)$ plotted as a function of orientation with reference to the standard stereographic triangle.

\section{Discussion of Results}

Given the complexity of the relationship between primary creep, heat treatment and orientation for even a single alloy chemistry (Figures 4 and 5), it is obvious that a casual comparison of alloy to alloy data, based on very limited nominally $<100>$ oriented specimens, such as in Figure 2, can lead to misleading conclusions. For the purpose of discussion here, the nominal $<100>$ orientation shall refer to any orientation less than $15^{\circ}$ off $<100>$. A statistical approach without proper attention to the specimen orientation distribution within the allowable orientation domain may also lead to biases in quantitative estimates of average values of creep rupture life and elongation. Similar considerations apply to comparisons of columnar grain material in Figure 3(a) and single crystal material in Figure 3(b) with different heat treatments. Testing of columnar grain material using small diameter creep specimens is equivalent to testing single crystal material. It is known that specimen ovalization occurs in columnar grain specimens as much as it does in single crystal. Thus data presented in Figures 2 and 3 must be considered indicative of trends, but no quantitative conclusions should be drawn.

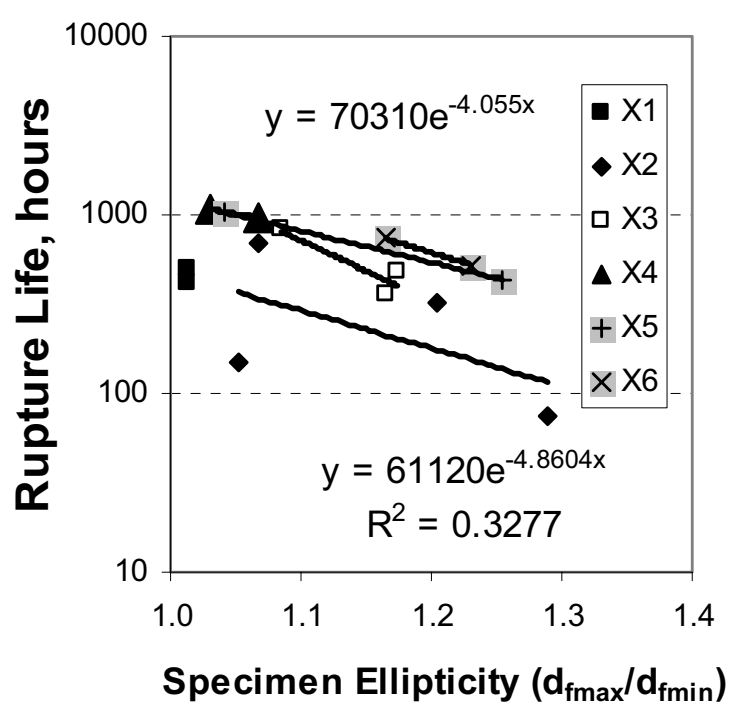

(a)

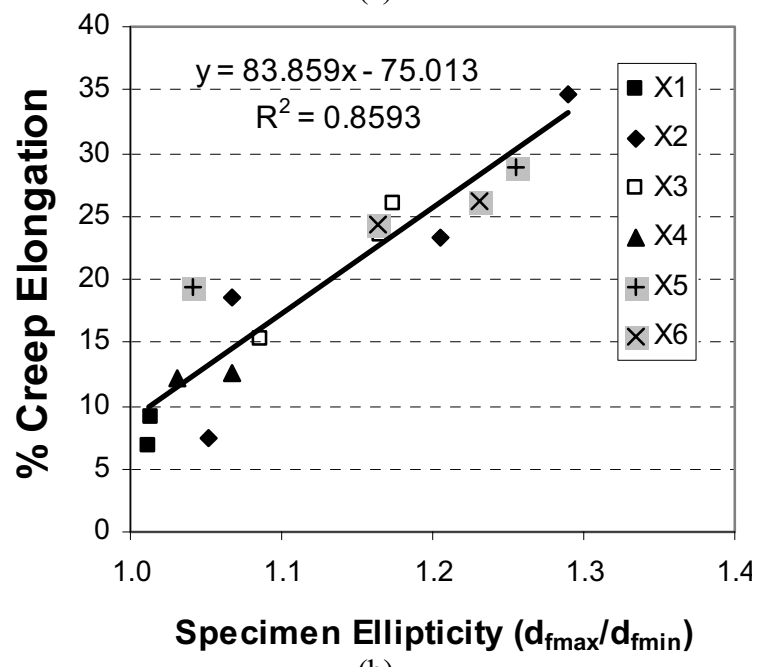

(b)

Figure $8.816^{\circ} \mathrm{C} / 621 \mathrm{MPa}\left(1500^{\circ} \mathrm{F} / 90 \mathrm{ksi}\right)$ (a) creep rupture life and (b) percent creep elongation versus specimen ellipticity of some $4^{\text {th }}$ generation alloys listed in Table II.

\section{Effect of Orientation}

A careful examination of creep curves in Figures 4(a) and 5(a) and corresponding orientations in Figures 4(b) and 5(b), respectively, show that in agreement with other published work [14], high primary creep tends to occur for orientation near the $<100>_{-}<111>$ boundary. Compare for example the behavior of specimen DL in Figure 4, and specimens IT3, HTS7, HTS8, HT11 in Figure 5, which are closer to the $<100>_{-}<111>$ boundary in the orientation triangle. Note from Table II that these are also the specimens that display large ellipticity. However, note that this correlation is not universal. As shown in Figure 7, two specimens from a $4^{\text {th }}$ generation experimental alloy X1, with orientations along the $<100>-<111>$ boundary, failed to show any significant ellipticity. While preceding comments are qualitatively true, correlating the creep rupture life, percent elongation and ellipticity of other specimens with non-descript orientation is obviously not easy, and to do so quantitatively seems hopeless. For example, 
compare the data for specimens $\mathrm{X} 5 \mathrm{a}$ and $\mathrm{X} 5 \mathrm{~b}$ in Figure 7. Even though Specimen X5b is further away from the $<100>-<111>$ boundary, compared to $\mathrm{X} 5 \mathrm{a}$, the former deformed more elliptically than the latter.

It has been shown that testing single crystal specimen of known or designed orientation present practical difficulties. As our data suggest, specimens machined from an individual, well characterized, single crystal bar can show wide scatter in behavior. These results, however, can be normalized by measuring post-failure specimen ellipticity. Part of the problem may be that superalloy single crystals are by no means perfect single crystals. Investment cast $<100>$ single crystal bars consist of a bundle of dendrites, $200-300 \mu \mathrm{m}$ in cross section and approximately ten times that in length. At best, only a dendrite can be considered an ideal single crystal. As is evident from Figure 1, a typical cross-section of a $3 \mathrm{~mm}$ gauge diameter specimen consists of roughly 100 dendrites. Given that dendrites, themselves are misoriented with respect to each other by approximately $2^{\circ}$, the orientation of any single crystal specimen cannot be defined any better than $\pm 2^{\circ}$. Add to this the error introduced by X-ray Laue technique, and it is obvious that the axial orientation of the specimen cannot be defined better than within a $2-4^{\circ}$ fuzzy zone. If this variation in axial orientation is enough to trigger either uniform or non-uniform plastic response, it is difficult to predict the mechanical response of the specimen based on its measured orientation. The situation is exasperated when the orientation is closer to $<100>$. For a single crystal oriented within $5^{\circ}$ from $\langle 100>$, it is difficult to pin down if the orientation is near the $<100>-<111>$ boundary or near the $<100>$ $<110>$ boundary. Thus there are inherent experimental difficulties in correlating the scatter in the data with measured average orientation. However, once the test is completed, the nature of plastic response is well reflected by the ovalization of the specimen gauge area. In the next section we shall attempt to answer why both the creep elongation and rupture life data correlate so well with the extent of ovalization or ellipticity, irrespective of the orientation.

\section{Relationship Between Elongation, Rupture Life, and Ellipticity}

Consider a general case of a cylindrical single crystal specimen subjected to a constant load $\mathbf{L}$, undergoing non-uniform deformation and the round cross section becoming elliptical. If $\mathbf{I}_{\mathbf{0}}$ and $\mathbf{l}$ are original and final gauge lengths, respectively; and $\mathbf{d}_{\mathbf{0}}$, $\mathbf{d}_{\mathbf{f m a x}}$, and $\mathbf{d}_{\text {fmin }}$ are initial, and final major and minor diameters, respectively, then volume conservation requires that elongation e\% be expressed as

$$
\mathbf{e} \%=100\left(\mathbf{l}-\mathbf{l}_{\mathbf{0}}\right) / \mathbf{l}_{\mathbf{0}}=100 \mathbf{d}_{\mathbf{0}}{ }^{2} /\left(\mathbf{d}_{\mathrm{fmax}} \mathbf{d}_{\mathrm{fmin}}\right)-100
$$

It can be seen from Table II that in most cases of elliptic deformation, no deformation occurs along the major diameters. Approximating $\mathbf{d}_{\mathrm{fmax}} \approx \mathbf{d}_{\mathbf{0}}$, percent elongation, $\mathbf{e} \%$, can be linearly correlated to the major to minor diameter ratio, $\left(\mathbf{d}_{\text {fmax }} / \mathbf{d}_{\text {fmin }}\right)$, with a slope of 100 .

$$
\mathbf{e} \% \approx 100\left(\mathbf{d}_{\text {fmax }} / \mathbf{d}_{\text {fmin }}\right)-100
$$

The principle of volume conservation is indisputable, and so there is no surprise that the creep elongation for both PWA1484 and all the experimental alloys correlates well with the measured ellipticity as shown in Figures 6(b) and 8(b), respectively. In both cases the slope and intercept of the best-fit straight line are close to 100 , as expected.

To understand the linear relationship between the logarithm of creep rupture life and ellipticity or the major to minor diameter

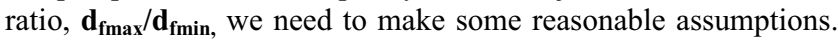
It is obvious that in a constant load creep test, true stress continually increases throughout the test as the specimen area decreases. Once again it is straight forward to show that initial stress $\sigma_{0}$, and final stress $\sigma_{\mathrm{f}}$, are given by:

$$
\begin{gathered}
\sigma_{0}=4 \mathbf{L} /\left(\pi \mathbf{d}_{\mathbf{0}}{ }^{2}\right) \\
\sigma_{\mathrm{f}}=4 \mathbf{L} /\left(\pi \mathbf{d}_{\mathrm{fmax}} \mathbf{d}_{\mathrm{fmin}}\right)=\sigma_{\mathbf{0}} \mathbf{d}_{\mathbf{0}}{ }^{2} /\left(\mathbf{d}_{\mathrm{fmax}} \mathbf{d}_{\mathrm{fmin}}\right)
\end{gathered}
$$

For engineering purposes the variation in true stress during a load controlled creep test is neglected on the implicit assumption that the source and magnitude of error introduced by the assumption is small and constant throughout the database. However, when some specimens deform uniformly and others non-uniformly on fewer slip systems, the implicit assumption is incorrect. Indeed, as calculated in Table II, final true stress for the specimens can increase anywhere from $3 \%$ to $48 \%$ from the initial stress depending on whether the deformation is uniform or non-uniform, respectively. Physically when a single crystal deforms by shearing on fewer slip systems, the strain is distributed more axially then transversely, and consequently the true stress increases disproportionately higher than it would if the specimen were to deform uniformly. If now, for the purpose of crude discussion, we assume that the creep rupture life is controlled by an average true stress, then we should expect a relationship between the creep rupture life $\mathbf{t}_{\mathrm{cr}}$ and the average true stress of the form

$$
\mathbf{t}_{\mathrm{cr}}=\mathbf{A}\left[\left(\sigma_{0}+\sigma_{\mathrm{f}}\right) / 2\right]^{-\mathbf{n}}
$$

where $\mathbf{A}$ is a constant of proportionality and $\mathbf{n}$ is a stress exponent of the order of 5-10.

Taking the logarithm of both the sides, and once again noting that minimal deformation occurs along one of the diameters, such that $\mathbf{d}_{\mathrm{fmax}} \approx \mathbf{d}_{\mathbf{0}}$, we can approximately correlate the creep rupture life to the diameter ratio as

$$
\log \left(\mathbf{t}_{\mathbf{c r}}\right)=\log (\mathbf{A})-\mathbf{n} \log \left(\sigma_{\mathbf{0}} / 2\right)-\mathbf{n} \log \left[1+\left(\mathbf{d}_{\mathbf{f m a x}} / \mathbf{d}_{\text {fmin }}\right)\right]
$$

Expanding the log function into a converging series and ignoring higher order terms, we can arrive at the following semi-log relationship between the rupture life and ellipticity.

$$
\log \left(\mathbf{t}_{\mathrm{cr}}\right) \approx \mathbf{B}-\mathbf{n}\left(\mathbf{d}_{\text {fmax }} / \mathbf{d}_{\text {fmin }}\right)
$$

In the above equation, the intercept $\mathbf{B}$ is expected to vary with material, temperature, and initial load or stress condition.

The validity of the relationship is well reflected by the semi-log plots of rupture life versus ellipticity in Figures 6(a) and 8(a). In Figure 6(a), data for PWA1484 with various heat treatments is very well normalized with a stress exponent of -5 . The implication that rupture life is not a strong function of heat treatment at $732^{\circ} \mathrm{C}\left(1350^{\circ} \mathrm{F}\right)$ is consistent with the creep curves presented in Figure 5(a), which show the same degree of scatter in data and correspondingly the same extent of distribution of orientation in Figure 5(b). 
In contrast, in Figure 8(a), while rupture life follows the same linear trend with ellipticity for various $4^{\text {th }}$ generation alloys, the data sets for individual alloys are shifted along the rupture life axis. The results show that X2 is one of the weakest alloys. As discussed before, the two specimens from alloy X1 are the most interesting. According to Figure 7, these specimens lie along the $<100>-<111>$ boundary, and yet show little ovalization. This suggests that for this specific alloy within a group of similar alloys, the creep behavior may show little sensitivity to orientation.

It must be emphasized that the discussion in the preceding two paragraphs is not meant to contradict the results presented in Figure 3, which shows that $\gamma^{\prime}$ size and distribution can profoundly influence the primary creep. On the contrary the clear message to be conveyed is, that such a comparison without a complete knowledge of orientation sensitivity and propensity of the alloy to deform non-uniformly for a given microstructure, can be misleading. Qualitatively we can only say that in general fine $\gamma$ microstructure is expected to lead to high primary creep, with enhanced tendency to deform non-uniformly and consequently greater sensitivity to orientation. However, quantitatively, the extent of behavior is a complex function of both temperature and stress as well as alloy chemistry.

\section{Relationship Between Time to 1\% and 2\% Creep and Ellipticity}

It can be argued that a correlation between rupture life and elongation, with ellipticity, is interesting but perhaps not as useful since, from a structural design standpoint, times to $1 \%$ or $2 \%$ creep are more relevant. As it turns out, times to $1 \%$ and $2 \%$ creep also correlate well with final ellipticity. As shown in Figures 9(a) and (b), for both PWA1484 at $732^{\circ} \mathrm{C} / 758 \mathrm{MPa}$ $\left(1350^{\circ} \mathrm{F} / 110 \mathrm{ksi}\right)$ and the $4^{\text {th }}$ generation alloys at $816^{\circ} \mathrm{C} / 621 \mathrm{MPa}$ $\left(1500^{\circ} \mathrm{F} / 90 \mathrm{ksi}\right)$, respectively, the correlation between the time to $1 \%$ and $2 \%$ creep and ellipticity is similar to that between rupture life and ellipticity. Of course the value of the exponent in the correlation equation differs in each case.

Even though the ellipticity used to correlate times to $1 \%$ and $2 \%$ creep was measured at rupture, it can be argued that the physical basis for the correlation is the same. Specimen ovalization is expected to be occurring all through the test, and so is the associated increase in true stress. The observed correlation is essentially a reflection of the fact that at any time during the test, the average true stress depends on how rapidly the specimen is ovalizing. The larger the ovalization is, the higher the true stress will be, and the greater the axial elongation. Both of these factors lead to a shorter time to achieve a fixed percent of strain.

\section{Creep Modeling Versus Suggested Data Normalization}

There is no doubt that many of the observations presented here can be rationalized by modeling creep in single crystals in terms of shear strain rate and resolved stress for all operative slip systems as has been proposed by L.-M. Pan et al. [13]. However, from the perspective of alloy development and heat treatment optimization, this approach would be cumbersome. Aside from that, there are several other issues that need to be addressed before the model can be used universally.
First, from the published work [13], it is not clear if the proposed model takes into account that true stress can rise at a different rate with differing extent of shape change during a constant load creep test. It can be argued that this aspect is not critical for small strains, but our correlation between time to $1 \%$ and $2 \%$ strain and ellipticity suggests that it is certainly not the case at those strain levels.

Secondly, the crystallographic nature of shape change, or thinning along $<110>$ direction as seen in Figure 1, is controversial. L.-M. Pan et al. [13] have been able to rationalize the shape change, invoking only the 12 normal octahedral $\{111\}<110>$ and 6 cube $\{100\}<110>$ slip systems. However, others insist that shape change cannot be explained without considering $\{111\}<112>$ slip mode [141.

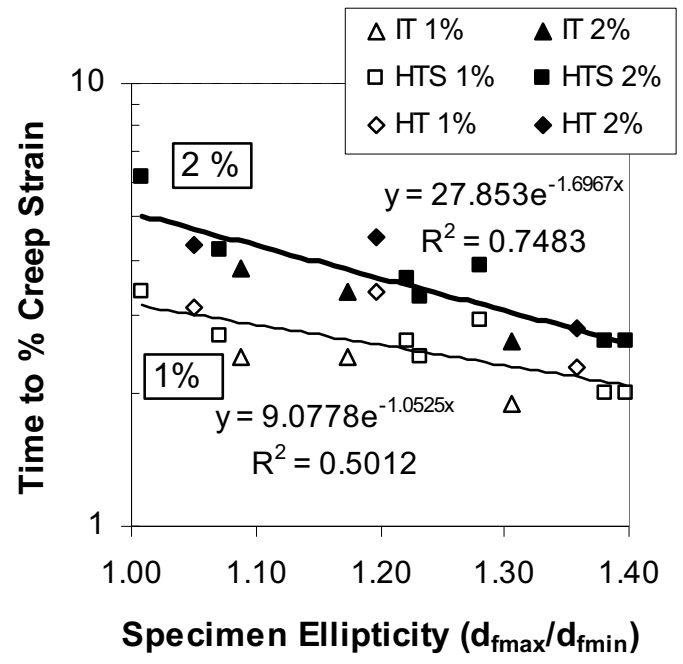

(a)

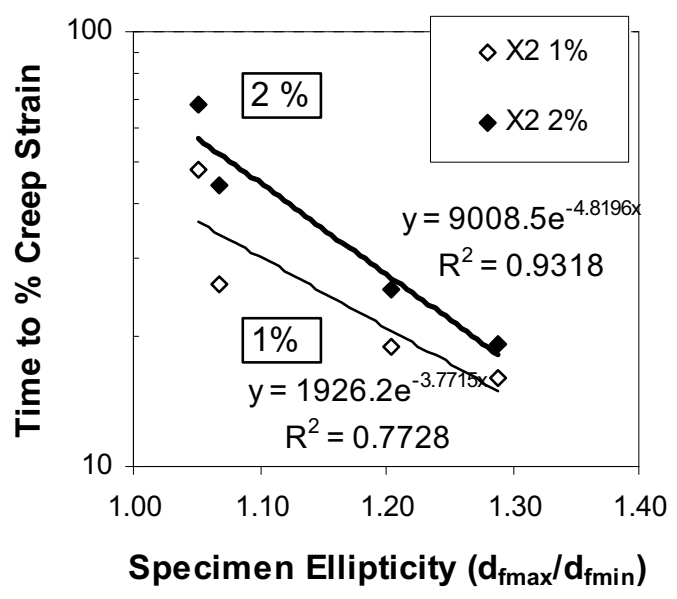

(b)

Figure 9 . Time to $1 \%$ and $2 \%$ strain versus specimen ellipticity at rupture for (a) PWA1484 with various heat treatments at $732^{\circ} \mathrm{C} / 758 \mathrm{MPa}\left(1350^{\circ} \mathrm{F} / 110 \mathrm{ksi}\right)$, and (b) for a $4^{\text {th }}$ generation alloy at $816^{\circ} \mathrm{C} / 621 \mathrm{MPa}\left(1500^{\circ} \mathrm{F} / 90 \mathrm{ksi}\right)$. 
The controversy of course is a moot issue with our correlations, as this aspect is not at all invoked. The normalization approach considered in this work circumvents the need to determine whether ovalization is a result of $\{111\}<110>$ or $\{111\}<112>$ slip systems. It seems the role of specific slip systems and supporting microstructural observations [14] may have been overplayed, though we believe it may be related to the extent of ovalization as discussed further.

The third, and perhaps the most critical issue, is related to the extent of ovalization itself. The key point to recognize is that there is clear evidence that the same degree of ovalization does not occur in all alloys with all heat treatments, for even the worst orientation along the $<100>-<111>$ boundary. That the creep model is unable to handle this is apparent from the remark by L.M. Pan et al. [13] "that it is not possible to resolve the tensile strain unambiguously into shear strains on each of the 18 slip systems that are active in single crystal superalloys." Recognize that the extent of shape change is controlled by the distribution of shear strains. There would be no ovalization, if the shear strains were uniformly distributed over all the operating slip systems. We believe that the ambiguity in regards to shear strain distribution results from the fact that microstructural features such as $\gamma^{\prime}$ size and $\gamma-\gamma^{\prime}$ misfit [9] which control the slip dispersion are not accounted for in the creep model.

How quickly the material distributes the axial strain into shear strains among different slip systems is as much a function of orientation as it is of the microstructure. It has been shown that in some alloys the deformation remains largely limited to the $\gamma$ channel [9], while in the others there is ample evidence of stacking faults [14]. The observation of stacking faults is generally considered a strong evidence in favor of $\{111\}<112>$ slip. A plausible scenario is that when deformation is limited to the $\gamma$-channels, the material quickly disperses the slip and settles to the steady state creep, leading to uniform deformation. However, if the microstructure and stresses are such that dislocations cut through $\gamma^{\prime}$ precipitates, the initial planar slip mode is not easily dispersed. High primary creep strains occur before the material settles into steady state creep mode. Further discussion of microstructural features and role of heat treatment, as well as residual strain due to $\gamma-\gamma^{\prime}$ misfit are beyond the scope of this paper.

There are still a lot of unanswered questions, such as how well the normalization presented here will work at lower stresses. We tend to test superalloys at high stresses in the laboratory, especially at intermediate temperatures, to limit lives to reasonable times. Then generally such data are extrapolated to lower stresses based on Larson-Miller type plots or an Arhennius-type relation between time and temperature. The other real question is, how important is the observed ovalization to a real component? Is ovalization strictly an artifact of unidirectional constant load laboratory creep testing of unrestrained single crystal bodies or does it have any relevance to thin walls of advanced airfoils, or creep relaxation in notches? There is no doubt that creep modeling is the right way to answer these questions [15], but once again we would suggest that it will be helpful if such modeling were done over a wide range of materials with contrasting slip dispersion capabilities.

\section{Summary}

Extreme variations in primary creep behavior and creep rupture life are commonly observed in nickel-base superalloys at intermediate temperatures, especially as evaluated at high stresses. The behavior is certainly a complex function of alloy chemistry and microstructure, as affected by even subtle changes in heat treatment. However, before such differences can be quantified, it is critical that non-uniform reduction in the specimen cross section - or ellipticity in case of cylindrical specimens - be taken into account. There is no doubt that specimen ovalization is due to the operation of a limited number of slip systems and is a systematic function of the crystal orientation of the specimen axis. Given the non-ideal nature of investment cast single crystals, the usual orientation information is not precise enough to correlate or apriori predict the plastic response of the specimens. Our analysis suggests that for nominally $<100>$ oriented crystals, the best approach is to test several specimens with diverse orientations and normalize the creep rupture data using specimen ellipticity. Results show that semi-log plots of rupture life versus ellipticity generally conform to a linear trend with an exponent of 4-5. Similar correlations also exist between time to a fixed percent strain and ellipticity, albeit with a different exponent. It is rationalized that under a constant load creep test, ovalization is a result of non-uniform transverse deformation leading to a disproportionately greater increase in true stress compared to a specimen deforming uniformly. Based on the principle of conservation of volume, observation of a linear correlation between creep elongation and ellipticity is fully reconciled. While the non-uniform deformation is a function of orientation and slip behavior when it is manifested, there are clear indications that it does not occur to the same extent in all cases. Small changes in alloy chemistries and heat treatments can quickly lead to activation of multiple slip systems and uniform plastic response, thereby curtailing the primary creep and leading to steady state creep, irrespective of the orientation. However, we are in no position to offer any insight into alloying trend, other than observing that in general presence of fine $\gamma$ in the microstructure tends to enhance orientation sensitivity and promote non-uniform deformation. While constitutive creep modeling based on shear strain rate for operating slip systems is the ultimate rigorous approach for analyzing creep response in single crystals, the assumed nature of shear strain distribution is structure sensitive and must be determined experimentally.

\section{Acknowledgement}

Many thanks are due to Mr. Robert Henricks (formerly of Pratt \& Whitney) for sharing some of the creep data, and Dr. Venkat Seetharaman for many insightful technical discussions. Thanks are also due to Mrs. Jennifer Clougherty and Mr. Albert Ivaldi for their enthusiastic help with creep testing and retrieving past data. 


\section{References}

[1] B.H. Kear and B.J. Piearcey, "Tensile and Creep Properties of Single Crystals of the Nickel-Base Superalloy Mar-M200", Trans. of the Met. Soc. of AIME, Vol. 239 (1967), 1209-1215.

[2] P.R. Paslay, C.H. Wells, and G.R. Leverant, "An Analysis of Primary Creep of Nickel-Base Superalloy Single Crystals", Trans. of the ASME - J. of Applied Mechanics, (Sept. 1970), 759-764.

[3] G.R. Leverant and D.N. Duhl, "The Effect of Stress and Temperature on the Extent of Primary Creep in Directionally Solidified Nickel-Base Superalloys", Met. Trans., Vol. 2 (1971), 907-908.

[4] Lin Donliang, Yao Delinang, and Sun Chuanqu, "The Effect of Stress and Temperature on the Extent of Primary Creep in Directionally Solidified Nickel-Base Superalloys", Superalloys $\underline{1984}$, ed. M. Gell, C. S. Kortovich, R. H. Brincknesll, W. B. Kent, and J. F. Radavich (Warrandale, PA: The Metallurgical Society of AIME, 1984), 199-210.

[5] P. Caron, Ohta, Y., Nakagawa, Y.G., Khan, T., "Creep Deformation Anisotropy in Single Crystal Superalloys", Superalloys 1988, ed. S. Reichman, D.N. Duhl, G. Maurer, S. Antolovich, and C. Lund (Warrandale, PA: The Metallurgical Society, Inc., 1988), 215-224.

[6] Koji Kakehi, "Effect of Primary and Secondary Precipitates on Creep Strength of Ni-Base Superalloy Single Crystals", Materials Science and Engineering, A278 (2000), 135-41.

[7] D.M. Shah and A. Cetel, "Creep Anisotropy in Nickel-Base $\gamma$, $\gamma^{\prime}$, and $\gamma / \gamma^{\prime}$ Superalloy Single Crystals", Superalloys 1996, ed. R. D. Kissinger, D.J. Deye, D.L. Anton, A.D. Cetel, M.V. Nathal, T..M. Pollock, and D.A. Woodford (Warrandale, PA: The Metallurgical Society, Inc., 1996), 273-282.

[8] D.M. Shah and D.N. Duhl, "Effect of Minor Elements on the Deformation Behavior of Nickel-Base Superalloys", Superalloys $\underline{1988}$, ed. D. N. Duhl, G. Maurer, S. Antolovich, C. Lund, and S. Reichman, (Warrandale, PA: The Metallurgical Society, Inc., 1988), 693-702.

[9] T. Pollock and A. Argon, "Creep Resistance of CMSX-3 Nickel Base Superalloy Single Crystals", Acta Metall. and Mater., Vol. 40(1) (1992), 1-30.

[10] S. Miura, Hayashi, T., Takekawa, M., Mishima, Y., Suzuki, T., "The Compression Creep Behavior of $\mathrm{Ni}_{3} \mathrm{Al}-\mathrm{X}$ Single Crystal", Materials Research Society Symposium, Vol. 213, Materials Research Society (1991), 623-628.

[11] W. Zhu, Fort, D. , Jones, I. P., and Smallman, R. E., "Orientation Dependence of Creep of $\mathrm{Ni}_{3} \mathrm{Al}$ at Intermediate Temperature", Acta. Mater., Vol. 46(11) (1998), 3873-3881.

[12] W. Zhu, Fort, D. , Jones, I. P., and Smallman, R. E., "On the Primary Creep of $\mathrm{Ni}_{3} \mathrm{Al}$ ”, Phil. Mag. Letters, Vol. 77(6) (1998), 307-313.
[13] L. -M. Pan, B. A. Shollock, and M. McLean, "Modelling of High-Temperature Mechanical Behavior of a Single Crystal Superalloy", Proc. R. Soc. Lond. A, Vol. 453 (1997), 1689-1715.

[14] C. M. F. Rae, Matan, N., Cox, D.C., Rist, M.A., and Reed, R.C., "On the Primary Creep of CMSX-4 Superalloy Single Crystals", Metallurgical and Materials Transactions A, Vol. 31A (2000), 2219-2228.

[15] D.W. MacLachlan, Wright, L.W., Gunturi, S.S.K., and Knowles, D.M., "Modelling the Anisotropic and Biaxial Creep Behavior of Ni-Base Single Crystal Superalloys CMSX-4 and SRR99 at 1223 K", Superalloys 2000, ed. T.M Pollock, R.D. Kissinger, R.R. Bowman, K.A. Green, M. McLean, S. Olson, and J.J. Schirra (Warrandale, PA: The Metallurgical Society, Inc., 2000), 357-366. 